\title{
Dual Social Effect of Internet Mass Incidents on Social Stability
}

\author{
Yanning Gao, Haihe Jin
}

School of Public Management, Inner Mongolia University, Hohhot 010021, China

Keywords: Internet mass incidents; social stability; dual social effect; interactivity between vitality and reality.

\begin{abstract}
In recent years, the internet mass incidents already become a prominent problem that affects the social stability in China. Under the new circumstance, the research on the dual social effect of internet mass incidents on social stability has practical significance and theoretical values. Firstly, the negative social effect of internet mass incidents on social stability was analyzed. Afterwards, the positive social effect of internet mass incidents on social stability was analyzed. Lastly, it proposed the suggestion for the government to avoid the negative social effect of internet mass incidents on social stability and fully play its positive social effects, such as improve the interest expression mechanism, enhance the information regulation and establish a positive interaction between the government and netizens.
\end{abstract}

\section{Introduction}

In recent years, the scholars in China have had in-depth research on the internet mass incidents continuously and achieved great outcomes. Jie Ping, Xiao Baomei discussed the components and coping strategy of internet mass incidents [1]: Liao Fangling, Gu Jinxi summarized internet mass incidents as 6 categories [2]; Peng Bo discussed in detail the laws of internet mass incidents [3]. Table 1 is the statistics about the related research in recent years. However, research on the social effect of internet mass incidents on social stability is still in blank. Based on the research results, the dual social effect of internet mass incidents on social stability will be analyzed in the paper.

Table 1 Internet mass incidents research summary table

\begin{tabular}{cccc}
\hline year & the number of journals & the number of newspapers & the number of dissertations \\
\hline 2010 & 47 & 5 & 4 \\
2011 & 75 & 3 & 15 \\
2012 & 80 & 2 & 18 \\
2013 & 9 & 0 & 0 \\
\hline
\end{tabular}

Most studies about the social effect of internet mass incidents are narrated from the practical level, which mainly analyzed its outward performance after the function played. In this case, it has negative and positive effect. The negative social effect can be an "amplifier" of unstable social factors, while the positive social effect could be the positive force that contributes to the social stability.

\section{Negative Social Effect of Internet Mass Incidents on Social Stability}

\subsection{Black Hole of Opinion Expression and “Tornado” of Cyber-Violence.}

On the one hand, the internet mass incidents have offered a platform for netizens to express their opinion freely; one the other hand, some irresponsible and uncommitted comments may generate: Some opinions are mixed up with extreme emotion, one-sided view, false truth and even wrong theory, this kind of false public opinion sometimes will stimulate the spreading of cyber violence, just as the futurist Negroponte thought each technology or science has its dark side. As for this irrational acceptance, Guo Liang proposed a reasonable explanation in his theory of DE individuation. Because of the shortage of system and moral restraint of internet mass incidents, sometimes you may find radical speech that neglect others' dignity and rights or even malicious slander. The internet mass incidents can easily become a harmful "cyber violence” and damage others' legitimate interest. As the French social psychologist le Bon believed that groups lack ability of dominate its reaction 
behavior [4]. This type of violence is very similar with the characteristics of tornado: fast speed of formation, short time of duration while have strong force and harms the society deeply. For example, the frequently occurred "cyber manhunt" sometimes may become "cyber violence".

\subsection{Information Distortion ---- A Chaotic “Bomb” in Real Life.}

According to the 25th statistical report of China Internet Network's development status, up to June 2014, the population of netizens in China reached 632 million, increased 14.42 million compared with the end of 2013, and the popularizing rate of internet was 46.9\%(see table 2), netizens have focused on the application of the various types of network is also one of the conditions of information dissemination (see table 3). Information distortion exists in the internet mass incidents, because anyone at different age, from different occupation, region, background could become a netizen of forum by registration or become a user of WeChat or set up their own blogs, and then release and forward related message through these platforms, which opens a door for false information and rumors. On the other hand, the development of internet mass incidents are driven by relevant interests, which mainly are reflected by indirect relevant interests, that is, the participant usually have no direct material interests with the event, but has potential correlation for interests, for instance, the expectation of social fairness and justice, and the pursue of ensuring the basic personal safety and dignity of the public.

Table 2 2009-2013 Chinese Internet user dimensions and Internet penetration

\begin{tabular}{ccc}
\hline year & Internet users (ten thousand) & Internet penetration \\
\hline 2009 & 38400 & $28.90 \%$ \\
2010 & 45730 & $34.30 \%$ \\
2011 & 51310 & $38.30 \%$ \\
2012 & 56400 & $42.10 \%$ \\
2013 & 61758 & $45.80 \%$ \\
\hline
\end{tabular}

(Source:http://www.cnnic.net.cn/hlwfzyj/hlwxzbg/hlwtjbg/201403/t20140305_46240.htm)

Table 3 Utilization ratio of variety of internet application among Chinese netizen

\begin{tabular}{cccccc}
\hline top 5 & \multicolumn{2}{c}{ in June 2014 } & \multicolumn{2}{c}{ in December 2013 } \\
\hline application & $\begin{array}{c}\text { the user scale (ten } \\
\text { thousand) }\end{array}$ & $\begin{array}{c}\text { netizens use } \\
\text { rate }\end{array}$ & $\begin{array}{c}\text { the user scale (ten } \\
\text { thousand) }\end{array}$ & $\begin{array}{c}\text { netizens use } \\
\text { rate }\end{array}$ & $\begin{array}{c}\text { the growth rate of } \\
\text { half a year }\end{array}$ \\
$\begin{array}{c}\text { instant } \\
\text { messaging }\end{array}$ & 56423 & $89.3 \%$ & 53215 & $86.2 \%$ & $6.0 \%$ \\
$\begin{array}{c}\text { search engine } \\
\text { internet news }\end{array}$ & 50749 & $80.3 \%$ & 48966 & $79.3 \%$ & $3.6 \%$ \\
$\begin{array}{c}\text { internet music } \\
\text { blog/personal }\end{array}$ & 50316 & $79.6 \%$ & 49132 & $79.6 . \%$ & $2.4 \%$ \\
space & 44430 & $77.2 \%$ & 45312 & $73.4 \%$ & $7.6 \%$ \\
\hline
\end{tabular}

(Source: http://www.cnnic.net.cn/hlwfzyj/hlwxzbg/hlwtjbg/201403/t20140305_46240.htm)

2.3 The Damage of Governmental Image: “Decomposer" of the Government's Public Credibility.

The concern about government occupies a large proportion of internet mass incidents. The reports about the some social phenomenon greatly damaged the government image, such as improper policy making, denial of justice and corruption of power etc. All these reports become the "decomposer" of the government's public credibility, which lead to the crisis of government credibility. The internet mass incidents make the public rights, public figures and all things related to the public interests under the focus of the public. In supervising the public rights, the public's impression on the government also changed.

\subsection{Internet Mass Incidents Become “Declaration” of Some Interest Groups.}

There are dynamic factors exist in the virtual society and real society that promote the netizens to attend the internet mass incidents, which involves with the gambling and competition among different social forces. Sometimes, the internet mass incidents will become the "declaration" of some interest group and lead to unbalance of online speaking right. Overall, internet mass incidents are a reflection of the public opinions, which deserves the high attention of decision-making executives on 
different levels. However, it must be pointed out that some internet mass incidents have enhanced the strength of some interest groups, so it is really difficult to tell whether the public opinions are true or false.

\section{The Positive Social Effect of Internet Mass Incidents on Social Stability}

The positive social effect of internet mass incidents on social stability was analyzed next, it was mentioned that the internet mass incidents could help the netizens to express their emotion, which could be helpful for the government to understand public conditions, restrict the public power and resolve social contradictions, so as to maintain the social stability.

\subsection{The "Safety Valve" for Social Stability".}

Firstly, the occurrence of internet mass incidents is the presentation for the netizens' individual development and the realization of self-values [5]. The development of internet technology brings the human into an era to fully express their own opinions, which is beneficial to the balance and promotion of mentality, consciousness and spirit. Secondly, the occurrence of internet mass incidents is also the presentation of netizens' emotion by free expressing their ideas, cognition, mentality and emotions, although there are restrictions in space, profession and social status. Netizens have common language among each other's on the internet and form group identification. Some unfairness, high pressure in work, grievance and resentment, all these emotions can be expressed and responded on the internet, so as to release the tension, relieve one's scare, loneliness and compensate one's regrets for unrealized dreams, and then bring a psychological balance and satisfactions to them. Those repressed emotions are not easily disappeared, if it don't passed with the collective irrational express manner, it could turn into other forms of destroying social stability behavior.

\subsection{Caution and “Alerted” for Social Development.}

The internet mass incidents are beneficial to the Party and the government to understand the public opinions, as it could reflect the social condition and public opinions as "alerted". China is in a status of social and economic transformation, so the social structure, interests' pattern and people's thought have had a profound change. The accumulated unfairness and grievance can be released through internet mass incidents. All kinds of false tendencies, including some unhealthy values nearly are all reflected on the internet. Each comment and sentences of the public on the internet are what the public concern. The internet mass incidents are the "mirror" for the real society. The government could find the existing problems in social development through the conveyed information from the internet mass incidents and understand the basic status of the netizens.

\subsection{Supervision by Public Opinions----A “Monitor” to Restrict Public Power.}

Numerous internet mass incidents indicate that the netizen have instinctive antipathy to the unfair social events and social evils, such as some social phenomenon as improper policy, denial of justice and corruption of power etc. Through different kinds of channels, the netizens could capture related information and timely be reflected by some internet mass incidents on the internet. In this sense, internet mass incidents have a function of supervision, which could promote the improvement of government's transparency and the benign development of society. As a result, the "Three major public expenses" are under the supervision of the public, which could promote the transparency of the society and its benign development. According to the People's Daily and People's Net joint to do an online survey in January 2009, 87.9\% of netizens participated in the survey are very concerned about the internet supervision, when faced with the social bad phenomenon, $93.3 \%$ of them choose to expose online. Internet mass incidents sometimes will convert quickly into the related departments' accountability and investigation. For instance Xiamen PX project, Yunnan hide-and-seek event, etc.

\subsection{An “Assistor” that Solves Contradiction and Promotes Policy Reform.}

At present, China already entered the rapid transformation period, in which the internet becomes an important tool for the public to safeguard their legal rights as the existence of various social contradictions and internet conflicts. Once social conflict occurs, the netizen usually tend to report the event through multimedia. If the government failed to response to the event timely or properly, it will become an internet mass incident soon, which can be best exemplified by "Wu Ken Event". 
Usually, the internet mass incident will draw the attention of numerous intellectuals. Afterwards, they tend to provide assistance for the appealer through the use of policy, rights protection, counseling of legal provision and media reports etc. Potentially, it promotes the progress for the reasonable settlement of the event. Lots of internet mass incidents are solved ultimately because of the pressure from the public opinion. Thus, the public have formed cognition that to appeal to the higher authority is inferior to report the event on the internet. It also illustrates that the internet mass incidents have an increasingly important effect on the decision making of the government, as the making and modification of some major public policies and legal provisions are triggered by internet mass incidents. Therefore, it is obvious that the internet mass incidents have become an "assistor" of policy reform.

\section{Discussion about the Governments' Countermeasures}

Internet mass incidents sometimes can bring more impact to the social stability, it tells us should pay attention to deal with the internet mass incidents from two aspects of virtual society and real society.

\subsection{Improve the Interest-Expressing Mechanism.}

In some ways, the occurrence of internet mass incidents has reflected the shortage of interest-expressing channels. When the public's interest demands can't be met through administration and judicial departments, they have no choice but turn to the informal way to express their appeal that is internet. Therefore, the government must improve their interest-expressing mechanism and remain smooth expressing channels for the public, so as to ensure the implementation of the public's right for expressing their demands.

\subsection{Enhance the Information Regulation: Establish a Dynamic Early Warning Mechanism.}

"Only with preparation can one be successful and vice versa". It is hard to tell the true or false of information on the internet, which makes it difficult to carry out the supervision on the information spreading on the internet as these information are often be speculated by some interest groups. Therefore, it is necessary for the government to establish and improve event trace mechanism on the internet mass incidents, analyze the report mechanism, monitoring mechanism and rapid handling mechanism to enhance the early period warning, process analysis and predication of online public opinion, so as to improve our capability in preventing and solving internet mass incidents, and then timely response to it, offer proper guidance and prevent the negative effect of the internet mass incidents from expanding.

\subsection{Establish a Benign Interaction with Netizens.}

Under the internet environment, the government have transformed into an active "partaker" from a positive "controller". Firstly, the government shall response to the internet mass incidents actively, release the objective and fair official information at the first time, so as to remove the public's doubts and guide the event to develop with a benign direction. As the mouthpiece of the government, the mainstream medium undertake an important responsibility to offer guidance of public opinion, and is a major source of social information. Once there is false or one-sided report exists in the mainstream media, all kinds of hearsay will take the advantage of this weak point and rapidly be accepted by the public. Besides, it is proved that the nations have far higher acceptability for negative information than positive information. Secondly, the government shall receive the supervision of netizens with an open-minded and tolerant spirit and form a consensus with the netizens in a benign interaction for solving the problems to establish an image as responsible governments, thereby to improve the government's public credibility and authority of public opinions.

\section{Conclusion}

This study regards the internet mass incidents in China as research background, analyzing the defects indwelling in available mechanisms and its influencing factors, trying to put forward the corresponding government countermeasures. The main conclusions are as follows: 
(1) Internet mass incidents is the "mirror" reflection of social reality, rooted in real society, in turn, it plays an important role in the real social. Internet mass incidents have dual social effect to social stability.

(2) On the one hand, internet mass incidents can lead to cyber violence, open a door for false information and rumors, damage the government image and become the "declaration" of some interest group; on the other hand, internet mass incidents can help the netizens to express their opinion freely, help the government to understand the public opinions, restrict public power and resolve social contradictions.

(3) In some ways, the occurrence of internet mass incidents has reflected the shortage of interest-expressing channels. The government should improve their interest-expressing mechanism and remain smooth expressing channels for the public, so as to ensure the implementation of the public's right for expressing their demands.

(4)Government should enhance the information regulation: establish a dynamic early warning mechanism. Government must enhance the early period warning, process analysis and predication of online public opinion, so as to improve our capability in preventing and solving internet mass incidents, and then timely response to it, offer proper guidance and prevent the negative effect of the internet mass incidents from expanding.

(5)Under the internet environment, the government have transformed into an active "partaker" from a positive "controller". Firstly, the government shall response to the internet mass incidents actively. Secondly, the government shall receive the supervision of netizens with an open-minded and tolerant spirit

\section{Reference}

[1] Jie Ping, Xiong Baomei. The internet mass incidents and its prevention. Jiangxi social sciences. Vol. 58 (2007) No. 9, p.238.

[2] Liao Fangling, Gu Jinxi. Challenge and countermeasures of internet mass incidents on government management. Zhejiang Academic Journal. Vol. 45 (2011) No. 1, p.217.

[3] Pengbo. The rule analysis of the internet mass incidents and prevention strategy study. Shanghai Jiao Tong University. Vol. 68 (2008) No. 1, p.17.

[4] Gustave Le Bon. The crowd-a study of the popular mind. Central Compilation \&Translation Press, 2005, p. 20.

[5] Zhang Xiaobing. Internet expression and social stability. Journal of Chinese People's Public Security University (Social Sciences Edition). Vol. 40 (2009) No. 3, p.40. 